\title{
Paranoid thinking, cognitive bias and dangerous neighbourhoods: Implications for perception of threat and expectations of victimisation
}

\begin{tabular}{|c|c|}
\hline Journal: & International Journal of Social Psychiatry \\
\hline Manuscript ID: & ISP-15-0005 \\
\hline Manuscript Type: & Original Article \\
\hline Date Submitted by the Author: & 11-Jan-2015 \\
\hline Complete List of Authors: & $\begin{array}{l}\text { Jack, Alexander; University of Nottingham, The Centre for Forensic and } \\
\text { Family Psychology } \\
\text { Egan, Vincent; University of Nottingham, The Centre for Forensic and } \\
\text { Family Psychology }\end{array}$ \\
\hline Keywords: & $\begin{array}{l}\text { Paranoia, Jumping to Conclusions, Threat, Victimisation, Heuristic } \\
\text { Reasoning, Psychosis }\end{array}$ \\
\hline Abstract: & $\begin{array}{l}\text { Background Information } \\
\text { Paranoid thinking is prevalent in the non-clinical population and cognitive } \\
\text { mechanisms of heuristic reasoning and jumping to conclusions bias } \\
\text { contribute to its formation and maintenance. } \\
\text { Aims } \\
\text { The present study investigated the degree to which paranoia, perceived } \\
\text { environmental risk, heuristic reasoning and jumping to conclusion bias } \\
\text { (measured with the beads task) contribute to misinterpretation of neutral } \\
\text { stimuli, and whether this informed judgements regarding vulnerability to } \\
\text { threat and crime. It is also investigated whether impulsiveness is a } \\
\text { confounding factor on the beads task. } \\
\text { Methods } \\
\text { Two hundred participants were recruited using a snowball-sampling } \\
\text { method for a quantitative cross sectional study. Participants reported } \\
\text { demographic information, three psychometric questionnaires and two } \\
\text { experimental tasks via an online paradigm hosted by the Bristol Online } \\
\text { Survey tool. } \\
\text { Results } \\
\text { Participants with high paranoia scores perceived their environment to be } \\
\text { more dangerous than those with low scores. Participants with high } \\
\text { paranoia scores also overestimated threat in neutral stimuli and had high } \\
\text { expectations of future victimisation. Jumping to conclusions on the bead } \\
\text { task did not predict fear of crime outcomes, but was predicted by } \\
\text { impulsivity. } \\
\text { Conclusions } \\
\text { Participants who demonstrated paranoid thinking were more likely to reside } \\
\text { in perceived dangerous neighbourhoods and overestimate threat. While } \\
\text { this could indicate a paranoid heuristic, it is a potentially rational response } \\
\text { to prior experiences of crime and victimisation. Implications and } \\
\text { suggestions for future research are discussed. }\end{array}$ \\
\hline
\end{tabular}




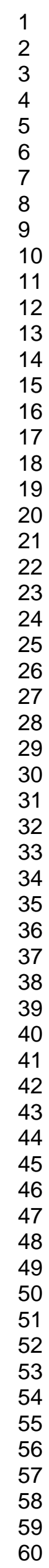

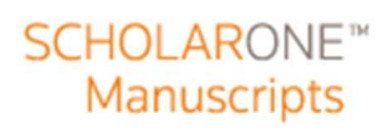

10

12

13

14

15

16

18

19

20

22

23

25

26

27

29

30

32

33

34

35

36

39

40

41

42

44

45

46

47

48

50

51

52

55

56

57

58

60

https://mc.manuscriptcentral.com/ijspsych 
Paranoid thinking, cognitive bias and dangerous neighbourhoods: Implications for perception of threat and expectation of victimisation.

\author{
Alexander H Jack * and Vincent Egan \\ Centre for Family and Forensic Psychology, YANG Fujia Building, University of \\ Nottingham, Wollaton Road, Nottingham, NG8 1BB, UK. (Email: \\ lwxaj4@exmail.nottingham.ac.uk; vincent.egan@nottingham.ac.uk). \\ *Corresponding author \\ For: International Journal of Social Psychiatry
}

Word Count: 3730

Running header: Paranoid thinking and expectation of victimisation

Date: Monday, $10^{\text {th }}$ January 2015 


\section{Abstract}

Background

Paranoid thinking is prevalent in the non-clinical population and cognitive mechanisms of heuristic reasoning and jumping to conclusions bias contribute to its formation and maintenance.

Aims

The present study investigated the degree to which paranoia, perceived environmental risk, heuristic reasoning and jumping to conclusion bias (measured with the beads task) contribute to misinterpretation of neutral stimuli, and whether this informed judgements regarding vulnerability to threat and crime. It is also investigated whether impulsiveness is a confounding factor on the beads task.

\section{Methods}

Two hundred participants were recruited using a snowball-sampling method for a quantitative cross sectional study. Participants reported demographic information, three psychometric questionnaires and two experimental tasks via an online paradigm hosted by the Bristol Online Survey tool.

Results

Participants with high paranoia scores perceived their environment to be more dangerous than those with low scores. Participants with high paranoia scores also overestimated threat in neutral stimuli and had high expectations of future victimisation. Jumping to conclusions on the bead task did not predict fear of crime outcomes, but was predicted by impulsivity.

\section{Conclusions}

Participants who demonstrated paranoid thinking were more likely to reside in perceived dangerous neighbourhoods and overestimate threat. While this could 
Paranoid thinking and expectation of victimisation

indicate a paranoid heuristic, it is a potentially rational response to prior experiences of crime and victimisation. Implications and suggestions for future research are discussed. 
PARANOID THINKING, COGNITIVE BIAS AND DANGEROUS

NEIGHBOURHOODS: IMPLICATIONS FOR PERCEPTION OF THREAT AND EXPECTATIONS OF VICTIMISATION.

\section{Introduction}

Delusional thinking (beliefs held to be true despite clear contradictory evidence; Freeman \& Garety, 2004) has attracted considerable investigation since the paradigmatic shift from categorical to continuum-based models of mental disorder (Garety \& Freeman, 2013). Thinking of a delusional nature has been shown to be prevalent in the non-clinical population (Johns \& van Os, 2001). For example, a study conducted by Verdoux, Maurice-Tison, Gay, van Os, Salamon and Bourgeois. (1998) reported that one in ten non-clinical respondents believed that they were the victim of a conspiracy. A more recent study by Cella, Sisti, Rocchi and Preti (2011) used latent class analysis to examine data in eight hundred young adults, finding forty-one per cent experienced paranoid thinking and a further thirty-one per cent held beliefs with delusional content. Another study (Freeman et al., 2005) found that approximately a third of non-clinical participants experienced paranoid thinking. In an experimental study, Freeman et al. (2008a) subjected 200 participants to a virtual reality train ride, populated by neutral characters. They found that a 'substantial minority' interpreted the neutral characters as threatening, with over forty per cent experiencing some paranoid thinking. There was also a positive association between self-reported paranoia and constructs derived from the virtual reality measure.

Whilst a number of cognitive mechanisms are associated with the formation and maintenance of paranoid thinking, "jumping to conclusions" (JTC) reasoning bias has been repeatedly implicated in experimental research looking at the phenomenon 
Paranoid thinking and expectation of victimisation: 2

(Garety \& Freeman, 2013). JTC is the tendency to use fewer data to reach a

conclusion before a reasoned decision can really be made. JTC bias is associated with the rapid appraisal of anomalous or ambiguous stimuli to form a delusional

conclusion without due consideration of alternative explanations (Garety \& Freeman, 2013).

A JTC bias has consistently been reported in individuals with delusional thinking, indicating that individuals with delusional thinking patterns accept hypotheses as correct on the basis of less evidence than controls (Fine, Gardner, Craigie \& Gold, 2007). Lincoln, Lange, Burau, Exner and Moritz (2010) found that individuals with active delusions required fewer beads before making a decision, and those with remissive delusions also required fewer beads than controls. So et al. (2012) corroborated these findings in a one-year longitudinal study, finding JTC bias prevalent in delusional clinical participants, and that this was stable across the period of study.

An association between paranoid thinking and JTC bias has also been shown in non-clinical populations. Freeman, Pugh and Garety (2008) demonstrated that approximately twenty per cent of participants displayed a JTC bias, and that this was highly associated with being more convinced by personally held paranoid beliefs. Persons can also JTC for a more prosaic reason than cognitive bias: impulsivity. Impulsivity crosses a variety of mental disorders (Moeller, Barratt, Dougherty, Schmitz, \& Swann, 2001) and may also affect performance as commission errors (i.e., the failure to withhold a response) has been seen for both human and animal studies (Wright, Lipszyc, Dupuis, Thayapararajah, \& Schachar, 2014; Bizot \& Thiébot, 1996). Whilst there is considerable literature highlighting the utility of the beads task, only one (Moritz \& Woodwood, 2005), to the author's knowledge, has controlled for 
impulsiveness. As psychotic individuals are reported to be more impulsive than controls (Lee et al., 2011), it is of value to exclude impulsivity as an explanation for JTC effects.

Misinterpretation of anomalous experiences is a valid contributing factor in the development and maintenance of paranoid delusional beliefs (Freeman \& Freeman, 2008, p105) and a JTC bias may indicate inaccurate appraisals of neutral stimuli (Garety \& Freeman, 2013). In research, paranoid individuals overestimate threat in neutral stimuli (Green \& Phillips, 2004); display attentional bias towards threatening stimuli (Salvatore et al., 2011); react quicker to 'paranoid words' than controls on an emotional Stroop test (Bentall \& Kaney, 1989); and perceive neutral faces as angry (Pinkham, Brensinger, Kohler, Gur \& Gur, 2011). The Freeman et al. (2008a) virtual reality study revealed that paranoid participants perceived threat in neutral characters within the virtual reality environment.

Evidence suggests that prior victimisation leads to the development of paranoid thinking (Mawby, 2007; Scott, Chant, Andrews, Martin \& McGrath, 2007). For example, Mawby (2007) reported that there was a significant association between repeat exposure to crime and increased negative feeling towards neighbours and neighbourhoods, as well as a consequent increased fear of crime. Furthermore, traumatic victimisation is reported to be causally associated with an increase in paranoid delusions (Scott et al., 2007). Increased exposure to crime can lead to heightened anxiety (Breslau, Davis Andreski \& Peterson, 1991) and in turn anxiety has been shown to contribute to the formation of paranoid thoughts (Bentall et al., 2009), with Freeman \& Garety (2003, p.923) stating: “... in many cases delusions are a direct representation of emotional concerns, and that emotion contributes to 
Paranoid thinking and expectation of victimisation: 4

delusion formation and maintenance" such that paranoid thinking can be described as “anxious fear" (Freeman et al., 2008b, p. 1130).

There is an increased risk of being a victim of crime in urban areas (Brennan, Moore \& Shepherd, 2010), and epidemiological studies report that urbanisation increases the risk of psychoses (Van Os, 2004; Sundquist, Frank \& Sundquist, 2004). Ellett, Freeman and Garety (2008) demonstrated how exposure to an urban environment exacerbated pre-existing paranoid thinking, heightened anxiety, negative beliefs about others and JTC reasoning bias. This conjunction of associations makes causality for victimhood, paranoia and fear of crime difficult to determine.

Heuristic reasoning (Tversky \& Kahneman, 1974) may explain how prior victimisation leads to paranoia. Corcoran et al. (2006) found participants used the availability heuristic to predict future negative events based on experience of past negative events. Bentall et al. (2008) found negative self-esteem and expectation of future negative events correlated with paranoid thinking, indicating that prior experiences contribute to future expectations. Bennett and Corcoran (2010) reported corroborating findings in paranoid participants. Lastly, Preti and Cella (2010) posit that a 'paranoid heuristic' may be employed by individuals to anticipate potential threat.

The present study sought to investigate whether non-clinical paranoid individuals use heuristic reasoning and JTC to interpret neutral stimuli and if so, how this informs the judgements they form regarding their vulnerability to threat and crime. It also examined if the JTC task is affected by simple impulsivity. It was hypothesised that: (1) there will be a positive association between living in a perceived dangerous neighbourhood and greater paranoid thinking; (2) participants who experience more paranoid thinking will overestimate threat / criminal intent, with 
perceived dangerous neighbourhoods and JTC bias acting as contributing factors; (3) greater paranoid thinking, more perceived dangerous neighbourhoods and higher JTC bias will predict high likelihood of crime expectations; and (4) that there will be a positive association between greater impulsiveness and JTC bias. The present study will allow for greater understanding of the interaction between paranoid thinking, perceptions of danger and expectations of crime, contributing to an understanding of how judgements grounded in paranoid thinking influence our experiences of everyday anxiety as the potential victim of a crime. Insight will also be achieved into the mechanisms and factors that contribute, such as affect and cognition.

\section{Method}

Design

A quantitative cross-sectional design was employed, utilising an opportunistic snowball-sampling method. All data was collected online using the Bristol Online Survey (BOS; http://www.survey.bris.ac.uk/); the survey was initially promoted on 'Facebook', 'Twitter' and the 'Psychological research on the net' websites. Participants were required to provide demographic information, respond to three standardised measures and complete two experimental tasks, all of which gathered information within the BOS architecture. The University ethics committee approved the study.

\section{Participants}

Two hundred participants (M:F = 85: 115) were recruited for the study; their age ranged from 17 to $67(\mathrm{M}=31.29, \mathrm{SD}=12.58)$. Eighty-one participants (40.5\%) reported themselves to be from an urban neighbourhood; 72 (36\%) reported to be from a suburban neighbourhood and 47 (23.5\%) from a rural neighbourhood. Fifty- 
Paranoid thinking and expectation of victimisation: 6

two $(26 \%)$ participants reported that they had previously been diagnosed with a mental illness with $24(12 \%)$ reporting depression, $10(5 \%)$ reporting anxiety and 7 (3.5\%) a dual diagnosis of depression and anxiety. A further $12(6 \%)$ reported other mental illness diagnoses.

\section{Measures}

Paranoia Scale (Fenigstein \& Vanable, 1992)

The paranoia scale is a twenty-item, self-report measure for the assessment of paranoia within a non-clinical population. Each item is rated on a five-point scale, ranging from one (strongly disagree) to five (strongly agree). Total scores range from twenty to one hundred, with higher scores indicating greater paranoid thinking (Freeman et al., 2005).

The paranoia scale is reported to have strong alpha internal consistency, with a reliability of 0.84 (Fenigstein \& Vanable, 1992).

Fear of Crime and Prior Victimisation Scale (Ferraro \& LaGrange, 1992)

\section{(Adapted)}

This assessment consists of two subscales, measuring fear of crime and likelihood of crime respectively. For the present study, only an adapted likelihood of crime subscale was utilised. The likelihood of crime subscale consists of ten items, with participants required to rate the likelihood of being a victim of each item within the next year. A five-point rating scale is used, ranging from one ("absolutely won't happen to me") to five ("will happen to me"). The "likelihood of being a victim in the next year' subscale is reported to have a strong alpha internal consistency, with reliability of 0.87 (Ferraro \& LaGrange, 1992).

Barratt Impulsiveness Scale (Short Form) (BIS-15; Spinella, 2007) 
The BIS-15 is an adapted short form of the BIS-II (Barratt \& Stanford, 1995).

It measures impulsivity across fifteen items, and is rated on a four-point scale (one equates to 'rarely/never' and four to 'almost always'). The BIS-15 was utilised in the present study so as to ascertain whether JTC bias can be accounted for by impulsiveness. The BIS-15 has a reliability of 0.79 , and a high correlation with the full BIS-II $(r=0.94)$ (Spinella, 2007).

\section{Beads Task (Garety et al., 2005)}

The beads task (Phillips \& Edwards, 1966) is a measure of cognitive reasoning to assess JTC bias. For the present study, a computerised version of the beads task (Garety et al., 2005) was adapted for use within the BOS. The task was as per standard instructions. The participant is presented with two jars: one had a ratio of 60:40 red to blue beads and the other had inverted proportions of the two colours (figure 1). The participant was informed that one of the jars has been chosen, and that beads can be drawn from it until a decision is made regarding which of the two jars was chosen (figure 2). The 'number of draws to decision' was used to score the task.

Insert Figures 1 and 2 here

\section{Perception of Criminal Intent Vignettes}

This measure consisted of ten neutral situational vignettes. Each vignette is designed to be realistic, mundane and internally consistent, in line with the recommendations of Wason, Polonsky and Hyman (2002). Each individual measure consisted of a neutral situational statement such as: "There has been a violent incident. A man is leaning over the victim and has blood on his shirt"; a neutral 
Paranoid thinking and expectation of victimisation: 8

instruction: "Based only on the above statement, use the scale to rate how much you agree with following statement"; and a possible conclusion: "The man has harmed the victim". Participants are asked to rate how strongly they agreed with the conclusion on a five-point scale, ranging from one (strongly disagree) to five (strongly agree). There were five subjective and five objective vignettes. Procedure

The measures were inputted into a research website using the BOS survey building tool. In order to host the images required for the beads task, a separate picture hosting website was developed (www.frpresearch.co.uk). The images were taken with permission from the computerised beads task (Garety et al., 2005) and sequenced appropriately.

Participants were recruited through a snowball sampling method, utilising online social media websites. A standardised message was created, with a link to the survey, and shared amongst the author's contacts. A request to forward the message to others was also included. While this meant that the survey could potentially reach an exponentially vast and heterogeneous audience, the BOS allowed for two hundred and fifty responses, over the sample size estimate of one hundred and fifty, and sufficient to accommodate any attrition in data and reduce the size of the confidence limits around the results of the study.

The full survey took approximately 20 minutes to complete. Upon completion, participants were advised to follow a link to the participant debrief. This was hosted on the same webpage as the beads task images. Results were automatically logged by the BOS system.

Statistical Analysis 
Paranoid thinking and expectation of victimisation: 9

Results were extracted from the BOS system and imported into SPSS 21.0 for analysis. All measures were found to be reliable, with Cronbach's alpha at minimum 'acceptable' for all tasks (table 1). Skewness and kurtosis were satisfactory for all measures, falling within desired parameters following the removal of one outlier.

Insert Table 1 here

\section{Results}

Hypothesis 1

To test the hypothesis that perceived dangerous neighbourhoods would be associated with paranoid thinking, a one-way ANOVA was run in order to ascertain which neighbourhoods were perceived to be most dangerous. The one-way ANOVA revealed that urban areas were perceived to be the most dangerous $(\mathrm{M}=1.91, \mathrm{SD}=.81)$. Perceived dangerousness differed significantly across neighbourhoods $(F(2,197)=$ 15.43, $\left.p=<.001, \eta_{\mathrm{p}}{ }^{2}=.14\right)$. Post hoc Bonferroni tests indicated that there were significant differences between urban and rural neighbourhoods $(p=<.001)$ and suburban and rural neighbourhoods $(p=.001)$. There was a non-significant difference between urban and suburban neighbourhoods $(p=.13)$. Results indicate that perceived dangerousness increases as the neighbourhood becomes more urbanised (table 2).

Insert Table 2 here 
Paranoid thinking and expectation of victimisation: 10

To test for an association between perceived dangerousness and paranoid thinking a bivariate correlation analysis was conducted. Results indicated that perceived dangerousness of neighbourhood was modestly, but significantly, related to paranoid thinking, $r=.145,95 \% \mathrm{CI}[-.023, .322], p=.04$.

\section{Hypothesis 2}

In order to investigate whether paranoid participants overestimated threat / risk of criminal victimisation, and whether JTC bias ${ }^{1}$, perceived dangerous neighbourhoods and mental illness contributed to the phenomenon, it was necessary to initially test for associations using a bivariate correlation analysis. Findings indicated that paranoid thinking was significantly associated with overestimation of threat / risk of criminal victimisation $(r=.321,95 \%$ CI $[.173, .502], p=<.001)$; however there were no significant associations between the other variables and overestimation of threat / risk of criminal victimisation (table 3).

Insert Table 3 here

In order to investigate the degree to which paranoid thinking predicted the overestimation of threat / risk of criminal victimisation, a simple linear regression analysis was conducted. Findings indicated that paranoia predicted the overestimation of threat / risk of criminal victimisation, $\beta=0.84,95 \%$ CI $[.033, .139] t(197)=3.35$,

\footnotetext{
${ }^{1}$ Scores of ' 1 ', ' 2 ' and ' 15 ' on the beads task were excluded from analysis due to the potential for participants to incorrectly complete the task. This resulted in 60 participants being excluded from all analyses that included the beads task.
} 
$p=.001$. Paranoia predicted $5.4 \%$ of the variation in outcome scores (adjusted $R^{2}=$ $.054)$

Hypothesis 3

In order to investigate whether paranoid thinking, perceived dangerous neighbourhoods, heuristic reasoning and JTC bias predict high likelihood of victimisation expectations, a bivariate correlation analysis was initially conducted to test for associations. Gender and mental health diagnoses were included in the analysis as potential contributing factors. Results indicated that gender, paranoid thinking and perception of neighbourhood as dangerous were all independently associated with high likelihood of crime expectations. To untangle the degree to which paranoia, perception of neighbourhoods as dangerous and gender could predict high likelihood of crime expectations; a multiple linear regression was conducted. Results indicated that a model constructed from paranoia, perception of neighbourhoods as dangerous, and gender predicted a significant proportion of variance in outcome scores, $R^{2}=.14, F(3,196)=10.664, p=<.001$. Adjusted $R^{2}$ indicated that the model accounted for $12.7 \%$ of the variance. Females were more likely than males to have high likelihood of victimisation expectations (table 4).

Insert Table 4 here

\section{Hypothesis 4}

To investigate whether impulsiveness is a confounding factor for JTC effect on the beads task, a two-tailed bivariate correlation analysis was conducted. Results 
Paranoid thinking and expectation of victimisation: 12

indicated significant negative correlations between total impulsiveness (and two of the three impulsiveness subscales) and scores on the beads task (table 5). This demonstrates that a JTC bias is associated with impulsiveness, specifically motor $(r=$ $-.215, p=.002)$ and non-planning impulsivity $(r=-.227, p=.007)$.

Insert table 5 here

\section{Discussion}

The results from this study support those of Johns and Van Os (2001), Cella et al. (2011), Freeman et al. (2008) and others who find a non-trivial prevalence of paranoid thinking in the general population. This is particularly apparent in urban environments, corroborating the findings of Sundquist, Frank and Sundquist (2004) and Ellett, Freeman and Garety (2011). Paranoia was also associated with greater perceptions of danger in increasingly urbanised neighbourhoods. Of particular significance were the findings that paranoid participants interpreted neutral social vignettes as containing threat / risk of criminal victimisation, supporting previous research (see Salvatore et al., 2011; Bentall \& Kaney, 1989; Pinkham et al., 2011), and had increased likelihood of victimisation expectations (see Bentall et al., 2008; Corcoran et al., 2006; Bennett and Corcoran, 2010). Interestingly, results did not find an association between paranoia and JTC bias, which is contrary to the existing published literature (e.g., Garety \& Freeman, 2013; Freeman, Pugh and Garety, 2008.). It was found however, that there was an association between impulsiveness and the beads task. 
Our study indicates that neighbourhoods perceived as dangerous may contribute to the development of an individual's paranoid thinking. Previous research has indicated that the risk of victimisation was increased in urban environments (Brennan, Moore \& Shepherd, 2010); that persons with mental vulnerability are more likely to be victims of crime (Hart, de Vet, Moran, Hatch, \& Dean, 2012), and that general paranoid thinking is greater within such neighbourhoods (Ellett, Freeman \& Garety, 2011). The availability heuristic (Tversky \& Kahneman, 1974) can be utilised to explain this association, as it is plausible that greater exposure to crime and victimisation can lead to greater fear (Mawby, 2007) and expectations of future victimisation (Bentall et al., 2008; Corcoran et al., 2006). Preti and Cella (2010, p. 264) posit that "paranoid ideation is not per se pathological but may, under certain circumstances, be even adaptive". The authors argue that paranoia is itself a heuristic that informs decision-making that maintains an individual's sense of security. The findings of the present study tentatively support this hypothesis.

The present study found that paranoid participants interpreted neutral social stimuli as containing threat thus indicating vigilance for potential harm. Vigilance for threat, identified in this study and previous research (for review see Green \& Phillips, 2004), can potentially be interpreted as an evolutionary and adaptive rational trait when the ecological niche suggests it is required (Preti \& Cella, 2010). The findings of the present study, that paranoid thinking and dangerous neighbourhoods predict high expectations of crime, appear to be rational and corroborate the explanation. Beads task

Findings relating to JTC bias in the present study were contrary to the existing published literature (see Garety \& Freeman, 2013) and no association was found between paranoid thinking and JTC bias; however, an association was found between impulsiveness and the beads task. The finding that there is not an association between 
Paranoid thinking and expectation of victimisation: 14

JTC bias and paranoid thinking in the current study is interesting; however, most significant research in support of the JTC phenomenon has been conducted with clinical samples (Garety et al., 2009) using the 85:15 ratio. Non-clinical research using the 60:40 proportions is less conclusive.

Perhaps more salient were the small association discovered between impulsiveness and the beads task. Motor and non-planning impulsiveness were significantly associated with the beads task, indicating that those who make decisions early on the beads task 'act on the spur of the moment' and 'do not think carefully about their actions' (Barratt \& Stanford, 1995). This would indicate that unless carefully administered by the researcher, the JTC effect is potentially confounded, especially in participants with psychosis (Lee et al., 2011). Future studies using the beads task to measure JTC bias should consider controlling for impulsiveness.

Despite these findings, the beads task results should be perhaps viewed with caution in the present study. Whilst the current study's adapted beads task made use of standardised instructions (Garety et al., 2005) it was apparent that a significant proportion of participants had difficulties following the procedure correctly. Scores of ' 1 ' and ' 2 ' were excluded from results due to the potential for comprehension errors as confounders. In future research, using the beads task outside of the laboratory, it is recommended that a practice run be conducted to maximise participant understanding, and the task further engineered to minimise such problems.

\section{Limitations of study}

The use of a snowball-sampling method allowed for considerable variance in the sample; however, the use of social media websites does create a potential selection bias; potentially excluding those populations most prone to paranoid thinking. Further limitations relate to the absence of certain measures from the present 
Paranoid thinking and expectation of victimisation: 15

study: It would have been advantageous to control for intelligence as a confounding factor on the beads task. Furthermore, as research indicates that worry and anxiety are factors in delusion formation (Freeman \& Garety, 2003) it would also have been beneficial to incorporate a reliable and valid anxiety measure into the present study, particularly as anxiety is a reported consequence of victimisation (Freeman and Freeman, 2008) and antecedent of paranoia (Bentall et al., 2009).

\section{Conclusion}

The findings from the present study add to existing literature on fear of crime, and provide further evidence that within the non-clinical population, individuals with a paranoid thinking style interpret threat in neutral stimuli and have high expectations of future victimisation; it is posited that dangerous neighbourhoods and use of availability heuristics contribute to this phenomenon. The present study also found an association between the beads task and impulsiveness; consequently, it is recommended that future studies utilising the measure control for impulsivity, and explore methods to increase ease of comprehension by participants.

Future research should further investigate the role of worry in expectations of victimisation, and the role that this plays in the formation of paranoid thinking. It is also important to further research how the use of paranoid heuristics (Preti \& Cella, 2010) informs judgements of criminal responsibility / intent and the degree to which this is pathological. This will allow for greater understanding of biases that inform everyday social decision-making.

\section{Conflict of Interest}

None.

\section{Funding}

This research received no specific grant from any funding agency in the public, commercial, or not-for-profit sectors. 
Paranoid thinking and expectation of victimisation: 16

\section{Supplementary materials}

Supplementary materials can be accessed via direct communication with the corresponding author. 
References

Barratt, E. S., \& Stanford, M. S. (1995). Impulsiveness. Personality characteristics of the personality disordered client. New York: Wiley, 91-119.

Bennett, K., \& Corcoran, R. (2010). Biases in everyday reasoning: Associations with subclinical anxiety, depression and paranoia. Psychosis, 2(3), $227-$ 237. DOI:10.1080/17522431003592649

Bentall, R. P., \& Kaney, S. (1989). Content specific information processing and persecutory delusions: an investigation using the emotional Stroop test. British Journal of Medical Psychology, 62(4), 355-364. DOI: 10.1111/j.20448341.1989.tb02845.x

Bentall, R. P., Rouse, G., Kinderman, P., Blackwood, N., Howard, R., Moore, R., ... \& Corcoran, R. (2008). Paranoid delusions in schizophrenia spectrum disorders and depression: the transdiagnostic role of expectations of negative events and negative self-esteem. The Journal of nervous and mental disease, 196(5), 375-383. DOI: $10.1097 / \mathrm{NMD} .0 \mathrm{~b} 013 \mathrm{e} 31817108 \mathrm{db}$

Bentall, R. P., Rowse, G., Shryane, N., Kinderman, P., Howard, R., Blackwood, N., ... \& Corcoran, R. (2009). The cognitive and affective structure of paranoid delusions: a transdiagnostic investigation of patients with schizophrenia spectrum disorders and depression. Archives of General Psychiatry, 66(3), 236-247. DOI:10.1001/archgenpsychiatry.2009.1.

Bizot, J. C., \& Thiébot, M. H. (1996). Impulsivity as a confounding factor in certain animal tests of cognitive function. Cognitive Brain Research, 3(3), 243-250. DOI: 10.1016/0926-6410(96)00010-9

Brennan, I. R., Moore, S. C., \& Shepherd, J. P. (2010). Risk factors for violent victimisation and injury from Six years of the british crime survey. International Review of Victimology, 17(2), 209-229. DOI: 10.1177/026975801001700204 
Paranoid thinking and expectation of victimisation: 18

Breslau, N., Davis, G. C., Andreski, P., \& Peterson, E. (1991). Traumatic events and posttraumatic stress disorder in an urban population of young adults. Archives of general psychiatry, 48(3), 216-222.

DOI:10.1001/archpsyc.1991.01810270028003.

Cella, M., Sisti, D., Rocchi, M. B., \& Preti, A. (2011). Delusional profiles among young adults: a latent class analysis of delusion proneness. Psychiatry research, 185(1), 97-101. http://dx.doi.org/10.1016/j.psychres.2010.04.054

Corcoran, R., Cummins, S., Rowse, G., Moore, R., Blackwood, N., Howard, R., ... \& Bentall, R. P. (2006). Reasoning under uncertainty: heuristic judgments in patients with persecutory delusions or depression. Psychological medicine, 36(08), 1109-1118. http://dx.doi.org/10.1017/S003329170600794X

Ellett, L., Freeman, D., \& Garety, P. A. (2008). The psychological effect of an urban environment on individuals with persecutory delusions: the Camberwell walk study. Schizophrenia research, 99(1), 77-84. DOI: 10.1016/j.schres.2007.10.027

Fenigstein, A., \& Vanable, P. A. (1992). Paranoia and self-consciousness. Journal of personality and social psychology, 62(1), 129. DOI: http://psycnet.apa.org/doi/10.1037/0022-3514.62.1.129

Ferraro, K. F., \& LaGrange, R. L. (1992). Are older people most afraid of crime? Reconsidering age differences in fear of victimization. Journal of Gerontology, 47(5), S233-S244. DOI: 10.1093/geronj/47.5.S233

Fine, C., Gardner, M., Craigie, J., \& Gold, I. (2007). Hopping, skipping or jumping to conclusions? Clarifying the role of the JTC bias in delusions. Cognitive Neuropsychiatry, 12(1), 46-77. DOI:10.1080/13546800600750597

Freeman, D., \& Freeman, J. (2008). Paranoia: The 21st century fear. Oxford, UK: Oxford University Press. 
Freeman, D., \& Garety, P. A. (2003). Connecting neurosis and psychosis: the direct influence of emotion on delusions and hallucinations. Behaviour research and therapy, 41(8), 923-947. DOI: 10.1016/S0005-7967(02)00104-3

Freeman, D., \& Garety, P. A. (2004). Paranoia: The psychology of persecutory delusions. Psychology Press.

Freeman, D., Garety, P. A., Bebbington, P. E., Smith, B., Rollinson, R., Fowler, D., ... \& Dunn, G. (2005). Psychological investigation of the structure of paranoia in a non-clinical population. The British Journal of Psychiatry, 186(5), 427435. DOI: 10.1192/bjp.186.5.427

Freeman, D., Gittins, M., Pugh, K., Antley, A., Slater, M., \& Dunn, G. (2008b). What makes one person paranoid and another person anxious? The differential prediction of social anxiety and persecutory ideation in an experimental situation. Psychological medicine, 38(08), 1121-1132. http://dx.doi.org/10.1017/S0033291708003589

Freeman, D., Pugh, K., \& Garety, P. (2008). Jumping to conclusions and paranoid ideation in the general population. Schizophrenia research, 102(1), 254-260. DOI: $10.1016 /$ j.schres.2008.03.020

Freeman, D., Pugh, K., Antley, A., Slater, M., Bebbington, P., Gittins, M., ... \& Garety, P. (2008a). Virtual reality study of paranoid thinking in the general population. The British Journal of Psychiatry, 192(4), 258-263. DOI: 10.1192/bjp.bp.107.044677

Garety, P. A., \& Freeman, D. (2013). The past and future of delusions research: from the inexplicable to the treatable. The British Journal of Psychiatry, 203(5), 327-333. DOI: 10.1192/bjp.bp.113.126953

Garety, P. A., Freeman, D., Jolley, S., Dunn, G., Bebbington, P. E., \& Fowler, D. G. (2009) FAQ ABOUT ADMINISTRATION OF THE BEADS TASK. Downloaded March $13^{\text {th }}, 2014$ from psychosisresearchpartnership.org.uk. 
Paranoid thinking and expectation of victimisation: 20

Garety, P. A., Freeman, D., Jolley, S., Dunn, G., Bebbington, P. E., Fowler, D. G., ... \& Dudley, R. (2005). Reasoning, emotions, and delusional conviction in psychosis. Journal of abnormal psychology, 114(3), 373 - 384 . DOI: http://psycnet.apa.org/doi/10.1037/0021-843X.114.3.373

Green, M. J., \& Phillips, M. L. (2004). Social threat perception and the evolution of paranoia. Neuroscience \& Biobehavioral Reviews, 28(3), 333-342. DOI: 10.1016/j.neubiorev.2004.03.006

Green, M. J., Williams, L. M., \& Davidson, D. (2003). Visual scanpaths to threat-related faces in deluded schizophrenia. Psychiatry research, 119(3), 271-285. DOI: 10.1016/S0165-1781(03)00129-X

Hart, C., de Vet, R., Moran, P., Hatch, S. L., \& Dean, K. (2012). A UK population-based study of the relationship between mental disorder and victimisation. Social psychiatry and psychiatric epidemiology, 47(10), 1581-1590. DOI: 10.1007/s00127-011-0464-7

Johns, L. C., \& van Os, J. (2001). The continuity of psychotic experiences in the general population. Clinical psychology review, 21(8), 1125-1141. DOI: 10.1016/S0272-7358(01)00103-9

Lee, T. Y., Kim, S. N., Jang, J. H., Shim, G., Jung, W. H., Shin, N. Y., \& Kwon, J. S. (2013). Neural correlate of impulsivity in subjects at ultra-high risk for psychosis. Progress in Neuro-Psychopharmacology and Biological Psychiatry, 45, 165-169. DOI: 10.1016/j.pnpbp.2013.04.008

Lincoln, T. M., Lange, J., Burau, J., Exner, C., \& Moritz, S. (2010). The effect of state anxiety on paranoid ideation and jumping to conclusions. An experimental investigation. Schizophrenia Bulletin, 36(6), 1140-1148. DOI: 10.1093/schbul/sbp029 
Paranoid thinking and expectation of victimisation: 21

Mawby, R. (2007). Public sector services and the victim of crime. In Walklate, S. (Editor), Handbook of Victims and Victimology. Cullompton, UK: Willan.

Moeller, F.G., Barratt, E.S., Dougherty, D.M., Schmitz, J.M., \& Swann, A.C. (2001). Psychiatric aspects of impulsivity. American Journal of Psychiatry, 158: 1783-1793. doi:10.1176/appi.ajp.158.11.1783

Moritz, S., \& Woodward, T. S. (2005). Jumping to conclusions in delusional and non-delusional schizophrenic patients. British Journal of Clinical Psychology, 44(2), 193-207. DOI: 10.1348/014466505X35678

Owen, M.J., O’Donovan, M.C., Thapar, A. \& Craddock, N. (2011). Neurodevelopmental hypothesis of schizophrenia, British Journal of Psychiatry, 198, 173-175. DOI: 10.1192/bjp.bp.110.084384

Phillips, L. D. \& Edwards, W. (1966). Conservatism in a simple probability inference task. Journal of Experimental Psychology, 72(3), 346-354. DOI: http://psycnet.apa.org/doi/10.1037/h0023653

Pinkham, A. E., Brensinger, C., Kohler, C., Gur, R. E., \& Gur, R. C. (2011). Actively paranoid patients with schizophrenia over attribute anger to neutral faces. Schizophrenia research, 125(2), 174-178. DOI: 10.1016/j.schres.2010.11.006

Preti, A., \& Cella, M. (2010). Paranoid thinking as a heuristic. Early intervention in psychiatry, 4(3), 263-266. DOI: 10.1111/j.1751-7893.2010.00190.x

Salvatore, P., Baldessarini, R. J., Tohen, M., Khalsa, H. M. K., SanchezToledo, J. P., Zarate Jr, C. A., ... \& Maggini, C. (2011). McLean-Harvard International First-Episode Project: two-year stability of ICD-10 diagnoses in 500 first-episode psychotic disorder patients. The Journal of clinical psychiatry, 72(2), 183. DOI: http://dx.doi.org/10.4088\%2FJCP.09m05311yel 
Paranoid thinking and expectation of victimisation: 22

Scott, J., Chant, D., Andrews, G., Martin, G., \& McGRATH, J. O. H. N. (2007). Association between trauma exposure and delusional experiences in a large community-based sample. The British Journal of Psychiatry, 190(4), 339-343. DOI: 10.1192/bjp.bp.106.026708

So, S. H., Freeman, D., Dunn, G., Kapur, S., Kuipers, E., Bebbington, P., ... \& Garety, P. A. (2012). Jumping to conclusions, a lack of belief flexibility and delusional conviction in psychosis: a longitudinal investigation of the structure, frequency, and relatedness of reasoning biases. Journal of abnormal psychology, 121(1), 129. DOI: http://psycnet.apa.org/doi/10.1037/a0025297

Spinella, M. (2007). Normative data and a short form of the Barratt Impulsiveness Scale. International Journal of Neuroscience, 117(3), 359-368. DOI:10.1080/00207450600588881

Sundquist, K., Frank, G., \& Sundquist, J. (2004). Urbanisation and incidence of psychosis and depression Follow-up study of 4.4 million women and men in Sweden. The British Journal of Psychiatry, 184(4), 293-298. DOI:

10.1192/bjp.184.4.293

Tversky, A., \& Kahneman, D. (1974). Judgment under uncertainty: Heuristics and biases. science, 185(4157), 1124-1131. DOI: 10.1126/science.185.4157.1124

Van Os, J. I. M. (2004). Does the urban environment cause psychosis?. The British Journal of Psychiatry, 184(4), 287-288. DOI: 10.1192/bjp.184.4.287

Verdoux, H., \& van Os, J. (2002). Psychotic symptoms in non-clinical populations and the continuum of psychosis. Schizophrenia research, 54(1), 59-65. DOI: 10.1016/S0920-9964(01)00352-8

Verdoux, H., Maurice-Tison, S., Gay, B., Van Os, J., Salamon, R., \& Bourgeois, M. L. (1998). A survey of delusional ideation in primary-care patients. Psychological medicine, 28(01), 127-134. DOI: http://dx.doi.org/ 
Paranoid thinking and expectation of victimisation: 23

1

2

3

4

5

6

7

8

9

10

11

12

13

14

15

16

17

18

19

20

21

22

23

24

25

26

27

28

29

30

31

32

33

34

35

36

37

38

39

40

41

42

43

44

45

46

47

48

49

50

51

52

53

54

55

56

57

58

59

60

Wason, K. D., Polonsky, M. J., \& Hyman, M. R. (2002). Designing vignette studies in marketing. Australasian Marketing Journal (AMJ), 10(3), 41-58. DOI:

10.1016/S1441-3582(02)70157-2

Wright, L., Lipszyc, J., Dupuis, A., Thayapararajah, S. W., \& Schachar, R. (2014). Response inhibition and psychopathology: A meta-analysis of go/no-go task performance. Journal of Abnormal Psychology, 123(2), 429-439. doi: 10.1037/a 
Paranoid thinking and expectation of victimisation: 24

1

2

3

4

5

6

7

8

9

10

11

12

13

14

15

16

17

18

19

20

21

22

23

24

25

26

27

28

29

30

31

32

33

34

35

36

37

38

39

40

41

42

43

44

45

46

47

48

49

50

51

52

53

54

55

56

57

58

59

60

https://mc.manuscriptcentral.com/ijspsych 
Paranoid thinking and expectation of victimisation: 25

1

2

3

4

5

6

7

8

9

10

11

12

13

14

15

16

17

18

19

20

21

22

23

24

25

26

27

28

29

30

31

32

33

34

35

36

37

38

39

40

41

42

43

44

45

46

47

48

49

50

51

52

53

54

55

56

57

58

59

60

https://mc.manuscriptcentral.com/ijspsych 
Figure 1: Standardised instruction screenshot for beads task

There are two jars: A mainly red jar containing

60 red and 40 blue beads and a mainly blue jar containing 60 blue and 40 red beads

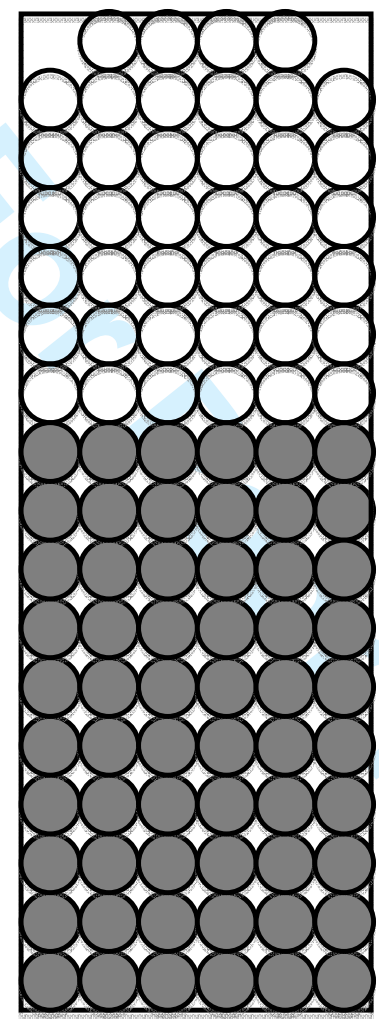

Mainly Red Jar:

60 red: 40 blue

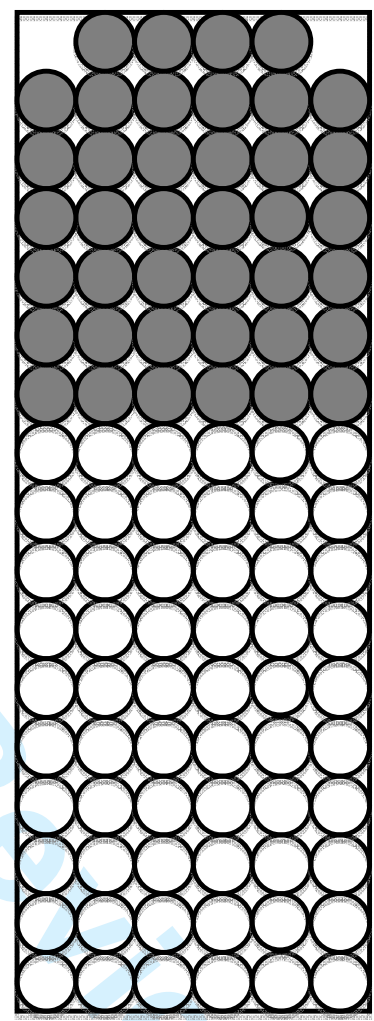

Mainly Blue Jar: 60 blue: 40 red

Table legend: shaded circles represent red beads, open circles blue beads. 
Page 31 of 35

International Journal of Social Psychiatry

1
2
3
4
5
6
7
8
8
9
10
11
12
13
14
15
16
17
18
19
20
21
22
23
24
24
25
26
27
28
29

The bead drawn is:

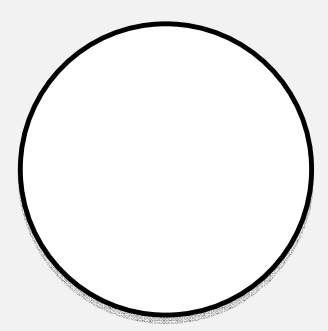

Would you like to see any more beads or have you decided now?

BEADS PREVIOUSLY SEEN

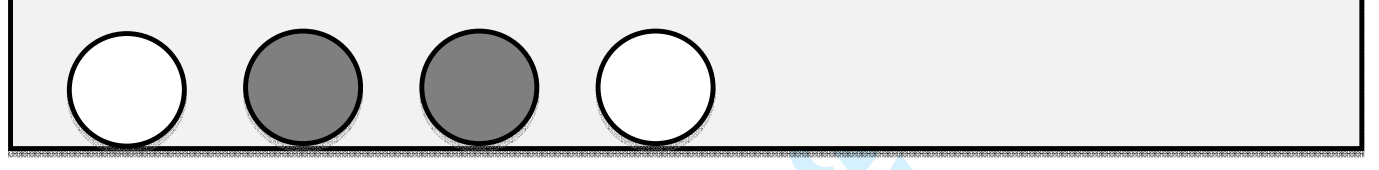

https://mc.manuscriptcentral.com/ijspsych 
Table 1: Cronbach's alpha, mean and standard deviations for measures utilised in the present study.

\author{
Cronbach's alpha Mean SD \\ Paranoia Scale \\ .913 \\ $48.24 \quad 13.60$ \\ Likelihood of Crime Scale \\ .854 \\ $25.81 \quad 5.91$ \\ BIS - 15 \\ Total \\ .818 \\ $39.61 \quad 6.80$ \\ Motor \\ .784 \\ 11.50 \\ 3.03 \\ Attention \\ .753 \\ $12.11 \quad 2.90$ \\ Beads Task \\ .959 \\ $10.10 \quad 2.96$ \\ Social Perception Vignettes \\ .781 \\ $28.71 \quad 4.92$ \\ $16.03 \quad 3.12$ \\ Non-planning $\quad .704$ \\ $10.10 \quad 2.96$
}

34

35

36

37

38

39

40

41

42

43

44

45

46

47

48

49

50

51

52

53

54

55

56

57

58

59

60 
Table 2: Descriptive statistics for perceived dangerousness ratings by neighbourhood.

\begin{tabular}{|c|c|c|c|c|c|c|}
\hline & & & & & $95 \%$ & confidence \\
\hline & & & & & interva & mean \\
\hline & $\mathrm{N}$ & Mean & SD & SE & lower & higher \\
\hline Urban & 81 & 1.91 & .81 & .090 & 1.73 & 2.09 \\
\hline Suburban & 72 & 1.68 & .73 & 086 & 1.51 & 1.85 \\
\hline Rural & 47 & 1.19 & .45 & .066 & 1.06 & 1.32 \\
\hline
\end{tabular}


Table 3: Correlation matrix describing associations between overestimation of threat / risk of criminal victimisation and variables; and high likelihood of victimisation expectations and variables.

\begin{tabular}{|c|c|c|c|c|c|c|}
\hline & \multicolumn{3}{|c|}{$\begin{array}{l}\text { Overestimation of threat / risk of } \\
\text { criminal victimisation }\end{array}$} & \multicolumn{3}{|c|}{$\begin{array}{l}\text { High likelihood of victimisation } \\
\text { expectations }\end{array}$} \\
\hline & $r$ & $p$ & $\mathrm{SE}$ & $r$ & $p$ & SE \\
\hline Paranoia & $\begin{array}{c}.321 \\
{[.173, .502]}\end{array}$ & $<.001 * *$ & .084 & $\begin{array}{c}.178 \\
{[.008, .356]}\end{array}$ & $.044^{*}$ & .084 \\
\hline Beads task & $\begin{array}{c}-.032 \\
{[-.171, .135]}\end{array}$ & .715 & .077 & $\begin{array}{c}-.015 \\
{[-.184, .180]}\end{array}$ & .865 & .094 \\
\hline $\begin{array}{l}\text { Dangerous } \\
\text { neighbourhood }\end{array}$ & $\begin{array}{c}.033 \\
{[-.167, .235]}\end{array}$ & .711 & .098 & $\begin{array}{c}.303 \\
{[.136, .414]}\end{array}$ & $<.001 * *$ & .071 \\
\hline Mental illness & $\begin{array}{c}-.020 \\
{[-.154, .187]}\end{array}$ & .820 & .088 & $\begin{array}{c}-.118 \\
{[-.271, .033]}\end{array}$ & .184 & .078 \\
\hline Gender & & & & $\begin{array}{c}.203 \\
{[.053, .381]}\end{array}$ & $.021^{*}$ & .080 \\
\hline $\begin{array}{l}\text { Overestimation } \\
\text { of threat / risk } \\
\text { of criminal } \\
\text { victimisation }\end{array}$ & & & & $\begin{array}{c}-.006 \\
{[-.209, .182]}\end{array}$ & .945 & .102 \\
\hline
\end{tabular}

Table Legend: $95 \%$ confidence intervals for $r$ reported in parenthesis. Confidence intervals and standard errors based on 140 bootstrap sample. * $p=<.005 * * p=$ $<.001$. 
Table 4: Variables that predict high likelihood of crime expectations

Paranoia

.071 $[.016, .114]$

$$
0.025 .163 .005^{*}
$$$$
1.832
$$

Dangerous Neighbourhoods

$$
[.914,2.724]
$$

$$
0.477 .236 .005^{*}
$$

\subsection{1}

Gender

$$
[.338,4.062]
$$

Table legend: Linear model of predictors of high likelihood of victimisation expectations, with 95\% confidence intervals reported in parenthesis. Confidence intervals and standard errors based on 200 bootstrapped samples $*$ significant $p=$ $<.005$ 
Table 5: Associations between impulsiveness and the beads task

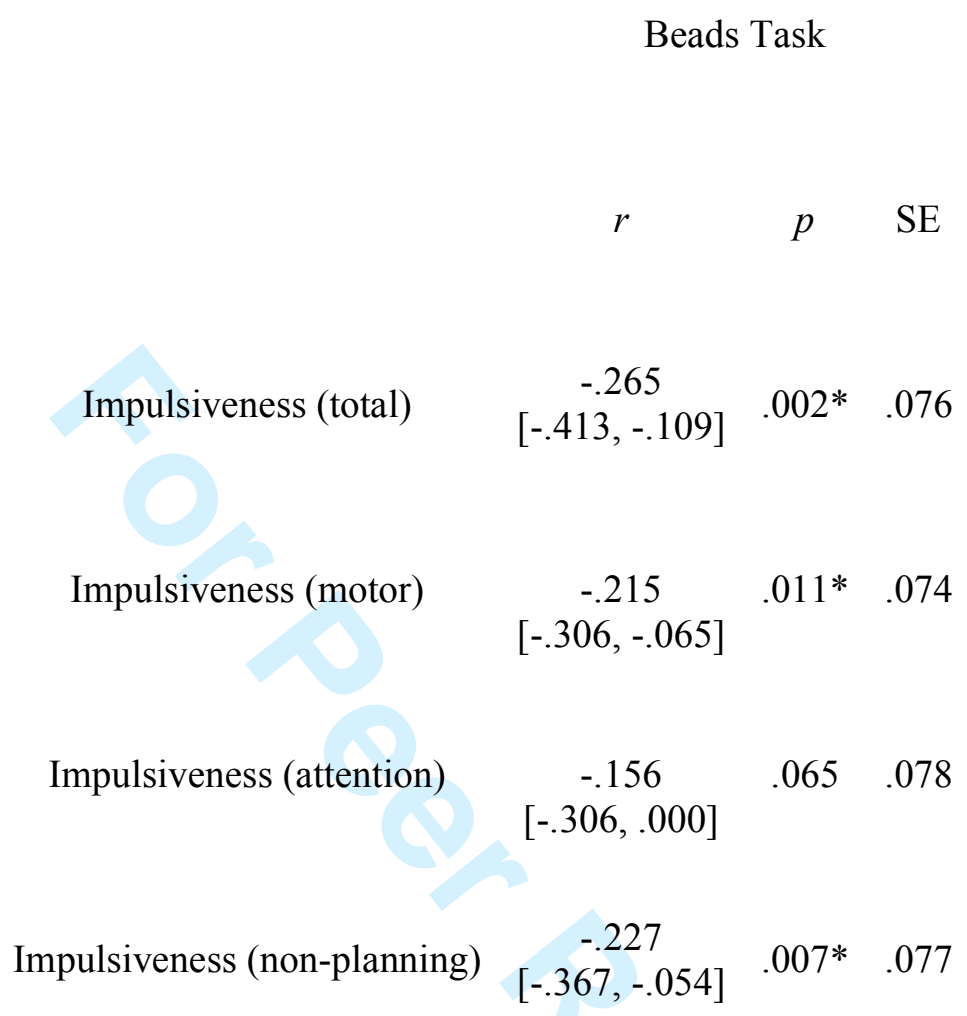

Table legend Correlation matrix describing associations between beads task and impulsiveness. 95\% confidence intervals for $r$ reported in parenthesis. Confidence intervals and standard errors based on 140 bootstrap sample. *significant $p=<.05$ 